iRASD Jounral of Economics
iRASD
Volume 1, Number 1, 2019, Pages $59-67$
JOURNAL EF ECONOMICS
Journal Homepage:
https://iournals.internationalrasd.org/index.php/ioe

\title{
The Assessment of Governance on Child Labor in evidence of Pakistan
}

Syed Wajahat $\mathrm{Ali}^{1}$, Faiqua Gul ${ }^{2}$

${ }^{1}$ Research Fellow, Society for Democracy and Human Development (SDHD), Email: Wajahat@sdhd.pk

${ }^{2}$ Willy Brandt School of Public Policy, University of Erfurt, Germany, Email: faiqua.gul@uni-erfurt.de

\section{ARTICLE INFO}

Article History:

Received:

Revised:

Accepted:

February 23, 2019

May 02, 2019

June 09, 2019

Available Online: June 30, 2019

\section{Keywords:}

Child Labor

Out of School Children

Governance

Economic Growth

Labor force participation

ARDL.

JEL Classification Codes:

F43, G34, J13, J21

\section{Funding:}

This research received no specific grant from any funding agency in the public, commercial, or not-forprofit sectors.

\section{ABSTRACT}

The aim of this study is to explore the impact of Governance on Child Labor. We all know, child labor is most pressing issue in developing countries and illiteracy, less per capita income, malnutrition and lack of development has added the impact. In article, we discussed the types of Governance and explores some other factors which impede and promote the public sector responsibilities towards children. We also highlighted the methodologies of assessment and performance of governments as protectors of children rights according to international commitments i.e. SDG's, In study, the dependent variable is Child Labor, while the independent variables are Governance, Population Growth Rate, Literacy Rate, Gross Domestic Product and Number of Schools. Time series data is used in range of 1990 to 2018. Augmented Dicky Fuller test is used to check the stationarity of the data. ARDL technique is applied on variables to check the long and short run relationship. The result shows an inverse relation between child labor and Governance, GDP, Literacy and number of schools as improvement in these indicators will decrease child labor. However, Population and child labor has a positive impact, by increasing population child labor will be increased. Impactful policies, good governance and better leadership are the only tools that can be helpful to tune child labor problem in developing countries.

(c) 2019 The Authors, Published by iRASD. This is an Open Access Article under the Creative Common Attribution Non-Commercial 4.0

\section{OPEN ACCESS}

Corresponding Author's Email: Wajahat@sdhd.pk
Citation: Ali, S. W., \& Gul, F. (2019). The Assessment of Governance on Child Labor in evidence of

Pakistan. IRASD Journal of Economics, 1(1), 59-67. https://doi.org/10.52131/joe.2019.0101.0005

\section{Introduction}

Child labor is a pervasive problem globally, particularly in developing countries. Child labor refers to the children who miss their childhood and are not able to access basic amenities which a child should have. Child labor mostly exists in rural \& semi-urban areas where the age for schooling and working is not defined. According to "Global Estimate of Child Labor: Results and Trend" of the International Labor Organization, estimated that there are around 218 million children between the ages of five to seventeen years who work globally. These children are often mistreated and worked for prolonged hours in hazardous which affects their physical, mental, and emotional health. A different study shows that poverty is a major factor that forces children for child labor because of their families (Mapaure, 2009).

Some studies like (Dessy \& Pallage, 2003) debated that not all child labor is harmful, work like sales, auto mechanic, babysitting, marketing, newspaper deliver related jobs enhance their technical skills until they are involved in psychological stress, human trafficking, prostitution, and physical/emotional harassment. International organizations have contributed huge efforts to eliminate child labor across the world. Even though low income countries have many constraints but still most of countries have opted for legislation to prohibit child labor. 
Many international organizations and research studies assumed that education is the key to eliminate child labor and it will help children to stay away from labor but not every family can afford schooling or, even if enrolled, retention is a challenge. Similarly, the Federal Bureau of Statics in Pakistan shows that approximately 19 million children under the age of 14 are working as child labor in Pakistan. However, Pakistan has a per-capita income of approximately $\$ 1350$ and on average each person in Pakistan only earns around $\$ 4 /$ day.

Governance is the concept to designate the efficiency, quality, and good interventions by the State. It introduces a "new form of government" in the global village. Good Governance support state and legislators to disseminate information sufficiently, accurately, and timely for appropriate actions, decision making, and future policies to carry out work more systematically and effectively. The term governance can apply to the corporate, international, national, local governance,-and interactions between other sectors of society. Good Governance can play a vital role in addressing child labor, countries experiencing good governance models have reduced child labor whereas corrupt and poor governance vulnerable child labor \& poverty. Presently, Pakistan is facing sewer governance challenges and the Government is putting all their efforts to bring reforms in Pakistan's Governance. As per the agreement of UN Sustainable development goal (SDG's), the government is liable to remove poverty from Pakistan by 2030.

In this study, we want to check whether Governance has played its role to counter child labor in Pakistan and to measure the impact of governance over child labor. According to the "Alif Ailaan District Ranking Report", almost 23 million children are still out of school in Pakistan and it shows massive child labor still exists in Pakistan (Ailaan, 2017).

The rest paper is organized as a literature review in section 2 , data \& methodology in section 3 , result $\&$ decision section 4 , and $5^{\text {th }}$ section compromises on conclusion $\&$ policy recommendation.

\section{Literature Review}

Kumar and Saqib (2017) highlighted a close association between school absenteeism, retention, grade repetition, lower academic achievement, high drop-out rate, health, and psychological disorders. He discussed children aged of $7-14$ have high school absenteeism in Bangladesh. In a study, the author empirically examines factors for school absenteeism \& child labor among children and numbers of a working hour in rural Bangladesh. Results show that parent's particularly mother literacy is most effected for child absenteeism and working hours for child labor. Student's especially female students from lower income home have higher absenteeism and greater working hour and their financial constraint emerge as barriers in retention. He discussed that if parental education can support children in schooling and child development through proper financing. The author concluded that there must be financial support and credit market to address the financial need for poor families \& students and government contribution through local aid or entrepreneurship can boost child participation in schools and achieving good academic grades.

According to Peters (2012), the UNICEF report of Governance and Rights of the Children highlighted the policies, implementation, monitoring, and governance structure to ensure child rights. The author discussed that Child Rights is a set of challenges to governments and divided it into fourfold, i) to implementation of legal commitments and legislation into action, ii) finding the appropriate political and governmental structure for implementation of programs and formation of dedicated governmental and non- governmental organizations to focus on policy area $\&$ to pursue the goals, iii) protecting the rights of children to coordinate all the various dimensions of a complex set of issues, iv) to evaluate and assessed the performance of governments in protecting the rights of children. As the implementation process is very important and crucial to evaluate the performances of programs. Thus, a detailed performance outline of the government in delivering these rights is required. To practice CRC conveniently, the government should also involve the actors including non-governmental organizations and institutions who have different expertise and interpretations to tune challenges in ensuring rights with frequent monitoring and evaluation. 
iRASD Journal of Economics, 1(1), 2019

Kim (2011) discussed how child labor is affected by the major factors in the Cambodian educational system. The author divided his research into two parts. In the first part, he discussed the Cambodian education sector and child labor solution by wider economic development. In the second part, he highlighted the major obstacles surrounding the education sector including governance and a wide gap between stated education policies \& ongoing practice. As a result, the majority of the children face challenges in achieving education, especially working children. The author concluded that major challenges including widespread corruption, insufficient national revenue, demotivation, and fewer skills in public services have made education \& policy implementation more complicated. Considering the challenges, greater political wisdom and practicing good governance can be effective in eliminating child labor and achieving universal basic education goals.

Chakrabarty, Grote, and Lüchters (2011) discussed the determinants of child labor, school going children in Nepal and examined the influence of social organizations (NGOs) who were engaged in social labeling on the incidence of child labor and school trade-off. The author debates that child labor is not only associate with household income but there are some more determinants of child labor. The study also presented that improving child and household welfare through the intervention of social labeling non-governmental organizations could be an effective way of increasing the number of school enrollments. For a policy purpose, the author suggested that technical, vocational \& financial training should be provided to adult members of the society which will increase the employment \& skilled labor in Nepal and contribute to household income and controls child labor. Similarly, a combination of policies like population control, access to credit market, finance loan \& welfare program should be available. The author concluded that by executing these action plans child labor will be decrease and NGOs can establish a positive influence on sending the ex-child laborers to school.

Fares and Raju (2007) asserted that the article has two-fold, first based on summary data at the country level for a usually a large set of developing countries originally obtained from household surveys conducted between 1993 and 2003. The Linear regression model and OLS technique were used in the model. In the article, the author created a detailed profile of children's economic activities, similarities, and differences across the region between genders. While the second fold was linked to country level data on child economic activities and child labor to country level indicators of the state of economics and social development in the same time period to find out the correlation among the identified literature data and other possible correlation if exists. It discussed that 5 out of 1 child works where economic activities are much better across the countries, whereas higher child labor ratio is 3 out of 1 child in poor economic activities rate. Boys are highly engaged in child labor activities as compared to girls in some regions depending on culture and traditions. Moreover, the highest child labor is found in agriculture, 10 out of 7 children work on different positions in agriculture. Similarly, the negative correlation found between child labor \& income, but this relation is not linear and indicates very low levels of income, and child labor is highly dependable over per capita income. The relationship between the child work and agriculture sector in the GDP is positive and significant due to the strong association of income.

Fasih (2007) analyzed the impact of legislation on child labor in Pakistan. The core objective of the article is to study whether ECA 1991 has played an effective role in falling child labor. The study used micro-level data from Pakistan's Integrated Household Survey 1991, (PIHS 1991). The data set consists of 35,774 individuals of all ages, in which 4480 are aged 10-14 with 2348 boys and 2132 girls. The author opted for regression discontinuity design created by the legislation defining 14 years of age (minimum age for work) and apply difference-in-difference estimation technique to isolate the effect of legislation from other effects upsetting child labor in Pakistan. The result presents a remarkable decrease in work for boys. However, socio-economic \& cultural values of the country resist employed girls likely to be involved in work outside the household. The law does not prohibit children from working with the family on family enterprise and results showed that the law is only beneficial for boys. 
Betcherman, Fares, Luinstra, and Prouty (2004) described the child labor definitions and legislations presented at multiple national and international forums, conventions, conferences including Universal Declaration of Human Rights 1948, International Covenant on Economic, Social and Culture Rights 1966, ILO $138^{\text {th }}$ convention 1973, Convention on the rights of the Child 1989, ILO Convention 1999. The article highlighted child labor impact socially \& economically and poor social \& welfare policies globally. Child Labor has different types; family farms, family businesses, prostitution, armed conflict, paid, and unpaid illegal activities. The author discussed that International and national campaigns could not achieve targets without addressing child labor and whereas household decision-making and policymaking is an effective tool to understand the phenomenon of child labor. The author concluded the study with the notes that children work for different reasons, sometimes to have a greater incentive due to expected education returns are lesser than the returns to work and families are not able to enroll their children in schools because of various challenges. These different circumstances need multi-sectoral approaches to address child labor and school participation can be boosted by increasing incentives, education reforms, quality of education, proper legislations, and implementations of policies.

According to Blunch, Canagarajah, and Goyal (2002), Child labor has received greater attention in the past years in developing countries and the majority of the analysis has been done on cross-sectional data. These researches were successful to highlight the determinants of child labor of single time due to cross section data and that support influencing policy options against child labor. The author discussed the void and analyze the dynamics of child labor and education system in Ghana and this study aimed to invest the impact of economic reforms on child labor and education in the short and long term. The logit model has been used in the study. i) a child has never attended school or works, ii) child has only attended school, iii) child attended both school \& works, iv) child works only. Further, this study concludes the association among child labor and poverty and found the asymmetric relationship among them and the dynamic relationship between child labor, schooling, and their determinants. In the short run, child labor is responsive of poverty, and in the long run, it is not effective, poverty significant effects schooling in the short run but effective in the long run. Hence concluded that child labor plays a significant role to increase the household in the short run and in the long run it has an insignificant effect.

Blunch and Verner (2000) examined the relationship among poverty and child labor, they used cross-section data and the model of estimation is Probit model because the dependent variable is in binary form 0 and 1.0 indicates that the child is not working and 1 indicates that the child is working. They discussed previous research questions that child labor is not destructive, and poverty has not to link with child labor. They analyzed the determinants that cause destructions in child labor and observed as child labor that differs children's accumulation of human capital. They re-establish the influence of poverty on child labor and frequent increase in child labor with age. This study also measures the occurrence and harmful determinations of child labor in Ghana and opted for a new sample to identify the vulnerable groups to make possible actions by legislators and policymakers. The author was successful to highlight the direct relationship between child labor and poverty and presented the gender gap evidence that linked child labor with poverty. They recommend that girls need more attention because they are highly affected as compared to boys.

\section{DATA AND METHODOLOGY}

In this research paper, we have analyzed the impact of governance on child labor in the case of Pakistan. Child labor $(\mathrm{CL})$ is proxied by children out of school and is a dependent variable, and exogenous variables are governance is measured by government effectiveness GE, economics growth GDPUS (GDP per capita \$), Population POP (Population growth rate), Education SSE (Secondary school enrollment) and labor LF (labor force participation rate). Mostly data is derived from World development indicators (WDI, 2018) and Government Effectiveness is taken from World Governance Indicators (WGI, 2018). The general form of the model is;

$$
C L=f(G D P U S, G O V, P O P, S S E, L F)
$$


iRASD Journal of Economics, 1(1), 2019

We used time series data and to check the order of the intergradation of the data we opted Augmented Dickey-Fuller (ADF) test. If the variables are at the order of intergradation I $(0)$ then the model will be estimated by the Ordinary Least Square (OLS) and if the variables have an order of integration I(1) then we used Johansen Cointegration Methodology and if the variables have mix order of intergradation then we can apply Auto Regressive Distributive lag (ARDL) model. So, very first we check the order of integration of the indicators.

\subsection{Augmented Dickey-Fuller test (ADF)}

In econometrics, statistics, and research, an augmented Dickey-Fuller test (ADF) tests the null hypothesis that a unit root is present in a time series sample. The alternative hypothesis could be varies depending on the test model version, but mostly it ranges between stationarity or trend-stationarity. However, for complicated and larger time series model augmented version of Dicky Fuller test is recommended. ADF and Dickey-Fuller tests have an identical process but ADF is only applicable on the models.

$\Delta y_{t}=\alpha+\beta_{t}+\gamma y_{t-1}+\delta_{1} \Delta y_{t-1}+\cdots \ldots .+\sigma_{p-1} \Delta y_{t-p+1}+\epsilon_{t}$

Where $\alpha$ is a constant, $\beta$ the coefficient on a time trend, and $\mathrm{p}$ is the lag order of the autoregressive process. Imposing the constraints $\alpha=0$ and $\beta=0$ corresponds to modeling a random walk and using the constraint $\beta=0$ corresponds to modeling a random walk with a drift. Hence, three main versions of the test are formed, similar to ones discussed on the Dickey-Fuller test.

In conducting the Dickey Fuller test, we assumed that the error term $\mu_{\mathrm{t}}$ is uncorrelated. But in the case, the assumption is violated and $\mu_{\mathrm{t}}$ is correlated. Augmented Dicky Fuller (ADF) test was developed by Dickey and Fuller, it is augmented by adding the lagged values of the dependent variable $\Delta \mathrm{Y}_{\mathrm{t}}$.

$$
\Delta Y_{t}=\beta_{1}+\beta_{2 t}+\delta Y_{t-1}+\alpha_{i} \Sigma \Delta Y_{t-i}+\varepsilon_{t}
$$

However, $\varepsilon_{t}$ is known as pure white noise error term and $\Delta Y_{t-1}=Y_{t-1}-Y_{t-2}$ as $\mathrm{i}=1$. It is serially uncorrelated and follows the same distribution as DF. Since the test is done over the residual term rather than raw data, it is not possible to use standard T-distribution to provide critical values. Therefore, this statistic $T$ has a specific distribution simply known as the Dickey-Fuller table.

The hypothesis is:

and $H 1: \delta \neq 0$

Decision rule:

If $t *>A D F$ critical value,$==>$ not reject null hypothesis, i. e., unit root exists.

If $t *<A D F$ critical value,$==>$ reject null hypothesis, i. e., unit root does not exist.

\subsection{Auto Regressive Distributive Lag (ARDL)}

Several econometric techniques are chosen to examine long-run cointegration relationship among variables, among the top are Engle and Granger (1987), fully modified OLS procedures of (Søren Johansen, 1988; S Johansen \& Juselius, 1990; Phillips \& Hansen, 1990) full information maximum likelihood procedures are widely used in empirical research. We know that, when variables are not at the same level of integration then Autoregressive Distributed Lag (ARDL) model suitable as it can deal with single cointegration analysis, ARDL was presented by Pesaran and Smith (1995) and later extended by Pesaran, Shin, and Smith (2001). Similarly, ECM is the best compatible model when all the variables have the same order of integration because of having characteristics to estimate long and short-run parameters estimation simultaneously (Azam, Nawaz, \& Riaz, 2019). We have applied ARDL because we find out that the order of integration of variables are mixed. And the equation 1 will become like; 


\subsection{Econometric Model}

$$
\begin{aligned}
& C L_{t}=\alpha_{o}+\sum_{i=1}^{p} \alpha_{1} \Delta C L_{t-1}+\sum_{i=0}^{p} \alpha_{2} \Delta G D P U S_{t-1}+\sum_{i=0}^{p} \alpha_{3} \Delta G O V_{t-1}+\sum_{i=0}^{p} \alpha_{4} \Delta P O P_{t-1}+\sum_{i=0}^{p} \alpha_{5} \Delta S S E_{t-1}+ \\
& \quad \sum_{i=0}^{p} \alpha_{6} \Delta L F_{t-1}+\alpha_{7} C L_{t-1}+\alpha_{8} G D P U S_{t-1}+\alpha_{9} G O V_{t-1}+\alpha_{9} P O P_{t-1}+\alpha_{10} \Delta S S E_{t-1}+ \\
& \quad \alpha_{11} L F_{t-1}
\end{aligned}
$$

\section{RESULTS AND DISCUSSIONS}

The yearly time series data for the period of 1996 to 2018 is taken and discussed "the impact of Governance over Child Labor". In this study, we measure the governance by Government effectiveness, child labor by out of school children, GDP per capita, population growth rate, secondary school education, and Labor force.

\subsection{Unit Root Test}

Table 1

Augmented Dicky Fuller Test

\begin{tabular}{llll}
\hline Variables & Level & 1st Difference & Results \\
CL & $0.0281 * *$ & & $\mathrm{I}(0)$ \\
GDPUS & 0.1435 & $0.0137 * *$ & $\mathrm{I}(1)$ \\
GOV & 0.1124 & $0.0261 * *$ & $\mathrm{I}(1)$ \\
POP & $0.0391 * *$ & & $\mathrm{I}(0)$ \\
SSE & 0.8382 & $0.0321 * *$ & $\mathrm{I}(1)$ \\
LF & 0.3048 & $0.0081 * *$ & $\mathrm{I}(1)$ \\
& & & \\
$* * *$ & & \\
\multicolumn{2}{l}{ level $5 \%$, and $*$ indicated significance level $1 \%$} \\
\hline
\end{tabular}

\subsection{ARDL Estimations}

Table 2

ARDL Estimation

\begin{tabular}{lcccc}
\hline \multicolumn{5}{c}{ Short run estimates } \\
Variable & Coeff. & S.E & T-stats & Prob. \\
C & -14.759 & 5.544 & -2.662 & 0.032 \\
@TREND & -0.087 & 0.024 & -3.627 & 0.008 \\
DLOG(ICL(-1)) & 0.676 & 0.258 & 2.622 & 0.034 \\
D(GOV) & -0.780 & 0.291 & -2.680 & 0.032 \\
D(SSE) & -0.009 & 0.017 & -0.524 & 0.616 \\
D(LF) & 0.166 & 0.048 & 3.455 & 0.011 \\
D(LF(-1)) & -0.308 & 0.072 & -4.288 & 0.004 \\
D(POP) & 1.209 & 0.506 & 2.390 & 0.048 \\
& Long-run Estimates of ARDL & & \\
Variable & Coeff. & S.E & T-stats & Prob. \\
GDDPUS & -0.047 & 0.011 & -4.196 & 0.004 \\
GOV & -0.270 & 0.127 & -2.130 & 0.071 \\
SSE & -0.024 & 0.009 & -2.672 & 0.032 \\
LF & 0.288 & 0.077 & 3.712 & 0.008 \\
POP & -0.382 & 0.156 & -2.444 & 0.045 \\
& Model Diagnostics & & \\
R-squared & & & & 0.923 \\
Adjusted R-squared & & & & 0.872 \\
\hline
\end{tabular}




\begin{tabular}{lc}
\hline Durbin Watson & 3.012 \\
LM-test & 0.114 \\
Heteroskedasticity-test & 0.377 \\
\hline$* * *$ indicates significance level 1\%, ** indicates significance level 5\%, and * \\
\hline
\end{tabular}

According to Table 1, few variables are stationary at a level including Child labor and population, however, Governance, GDP US, secondary school education, and labor force are stationary at first difference.

According to table 2, presents the short run and long run results of the GDP, Governance, Population, education, and labor force to child labor. Results indicate that governance and secondary school education are negative coefficients, however, labor force and the population is positively coefficient. Similarly, Governance, Labor force, population are significant but secondary school education is non-significant.

Long run estimation indicates that GDPUS, Governance, Secondary school education, and population are negative coefficient, while the labor force are positive coefficient. Similarly, the long-run result shows that all the selected variables are completely significant.

GDP per capita has a statistically significant and negative impact on child labor because financial support and credit markets addressed the financial needs of poor families and facilitate children in achieving education and good health (Kumar \& Saqib, 2017).

Governance has a statistically significant and negative impact on child labor as practicing appropriate political and government structure for implementation of programs and formation of government departments has increased the governance efficiencies which reduced child labor (Peter, 2012).

Secondary school education has a statistically significant and negative impact on child labor as many international organizations and researches said that education is the key tool to eliminate child labor (Dessy \& Pallage, 2003; Kim, 2011). Furthermore, Betcherman et al. (2004) confirm that school participation and quality education can boost incentives and reduce child labor.

The population has a statistically significant and negative impact on child labor as a combination of policies including population control programs and welfare programs have reduced the child labor ratio (Chakrabarty et al., 2011). Labor force has a statistically significant and positive impact on child labor because skilled adult labor can take start-up and avoid the risk of poverty and child labor (Chakrabarty et al., 2011).

According to model diagnostic table 4.2 , the R-squared value is 0.923 which means the exogenous variables explain almost $92 \%$ to child labor and the adjusted R-Squared values is 0.872 . Durbin Watson value is 3.012 which is greater than 1.96 , that indicates the model is a good fit and there is no chance of autocorrelation. Furthermore, LM test is used for autocorrelation which indicates that we must accept null hypothesis because LM prob value test is greater than $5 \%$ and does not have a problem of autocorrelation Breusch-PaganGodfrey is used to check the heteroskedasticity problem in the data, prob value is greater than $5 \%$, that indicates we accept the null hypothesis, which means that no heteroskedasticity problem exists in the model. Hence overall model diagnostic confirms that the model is unbiased and efficient. 


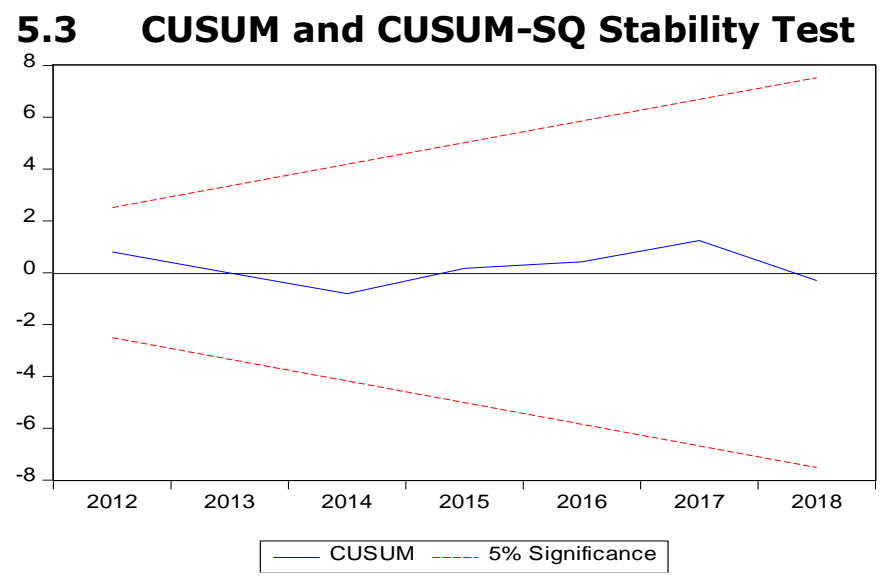

Figure 1: CUSUM Test

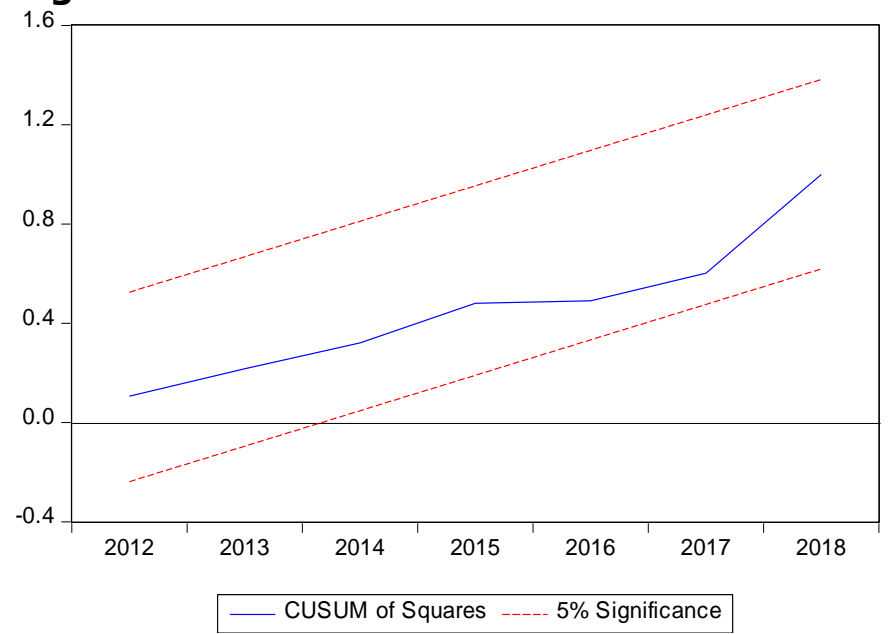

Figure 2: CUSUM SQ Test

CUSUM and CUSUM of a square test are used to check the stability of models. According to the above graphs, the estimated (blue) line lies between the standard deviation line, which confirms that the model is stable.

\section{Conclusion and Policy Recommendation}

The objective of the study was to examine the impact of governance over child labor in the case of Pakistan, along-with supporting variables of GDP US, Population, Secondary school education, and Labor force of the time period (1996 to 2018). However, the model is estimated by the Auto Regressive Distributive (ARDL) model.

We have observed that child labor is highly dependable over Governance performance, if Governance is good it will reduce child labor by implementing the demand of the public sector and legislations. Similarly, results indicate that GDP\$, Secondary school education, governance, and labor force have an inverse relation with child labor, however, the population has a positive relation with child labor.

The policy recommendations are that the government should properly activate the public institutions as it is essential for practicing good governance and policies execution. The demand of human rights is vital, and measurement of children's rights is very abstruse, there should be some dedicated research institutions and child rights protection departments and programs that work in close liaison with the government to achieve all the objectives of CRC. Furthermore, numerous actors have different priorities and interpretations of fundamental child rights, and these actors are involved in the procedure and give the most challenges in providing rights. Most importantly corruption, national revenues, the infrastructure of the system, political and economic crises should consider as a national problem, and through 
iRASD Journal of Economics, 1(1), 2019

proper planning, evaluation, monitoring and forecasting we can tune these problems and guaranteed for effective policies, implementations of legislations and ultimately good governance.

\section{Conflict of Interests/Disclosures}

The authors declared no potential conflicts of interest w.r.t the research, authorship and/or publication of this article.

\section{References}

Ailaan, A. (2017). Pakistan district education rankings 2016. Alif Ailaan, Islamabad, 66(1).

Azam, M., Nawaz, M. A., \& Riaz, M. (2019). Does Corruption and Terrorism Affect Foreign Direct Investment Inflows into Pakistan? Journal of Managerial Sciences, 13(2), 85-97.

Betcherman, G., Fares, J., Luinstra, A., \& Prouty, R. (2004). Child labor, education, and children's rights. World Bank Social Protection Discussion Paper Series, 412.

Blunch, N.-H., Canagarajah, S., \& Goyal, S. (2002). Short-and long-term impacts of economic policies on child labor and schooling in Ghana. Social Protection Discussion Papers.

Blunch, N.-H., \& Verner, D. (2000). Is functional literacy a prerequisite for entering the labor market? An analysis of the determinants of adult literacy and earnings in Ghana.

Chakrabarty, S., Grote, U., \& Lüchters, G. (2011). Does social labelling encourage child schooling and discourage child labour in Nepal? International Journal of Educational Development, 31(5), 489-495.

Dessy, S., \& Pallage, S. (2003). The economics of child trafficking. Centre Interuniversitaire sur le Risqué, les Politiques, Economiques et l'Emploi, University of Quebec.

Engle, R. F., \& Granger, C. W. (1987). Co-integration and error correction: representation, estimation, and testing. Econometrica: journal of the Econometric Society, 251-276.

Fares, J., \& Raju, D. (2007). Child labor across the developing world: Patterns and correlations: The World Bank.

Fasih, T. (2007). Analyzing the impact of legislation on child labor in Pakistan: The World Bank.

Johansen, S. (1988). Statistical analysis of cointegration vectors. Journal of economic dynamics and control, 12(2-3), 231-254.

Johansen, S., \& Juselius, K. (1990). Maximum likelihood estimation and inference on cointegration-with appucations to the demand for money. Oxford Bulletin of Economics and statistics, 52(2), 169-210.

Kim, C.-Y. (2011). Child labour, education policy and governance in Cambodia. International Journal of Educational Development, 31(5), 496-504.

Kumar, A., \& Saqib, N. (2017). School Absenteeism and Child Labor in Rural Bangladesh. The Journal of Developing Areas, 51(3), 299-316.

Mapaure, C. (2009). Child labour: A universal problem from a Namibian perspective. Children's Rights in Namibia, 201-222.

Pesaran, M. H., Shin, Y., \& Smith, R. J. (2001). Bounds testing approaches to the analysis of level relationships. Journal of applied econometrics, 16(3), 289-326.

Pesaran, M. H., \& Smith, R. (1995). Estimating long-run relationships from dynamic heterogeneous panels. Journal of econometrics, 68(1), 79-113.

Peter, B. G. (2012). Governance and The Rights of Children. UNICEF Office of Research Working Paper, WP 2012-11, 31.

Peters, B. G. (2012). Governance and the Rights of Children: Policy, implementation and monitoring.

Phillips, P. C., \& Hansen, B. E. (1990). Statistical inference in instrumental variables regression with I (1) processes. The Review of Economic Studies, 57(1), 99-125.

WDI. (2018). World Development Indicators. from The World Bank https://databank.worldbank.org/source/world-development-indicators

WGI. (2018). Worldwide Governance Indicators. from The World Bank https://databank.worldbank.org/source/worldwide-governance-indicators 